\title{
Perioperative Management of Endocrine Active Adrenal Tumors
}

\section{Authors}

Florentine Schreiner ${ }^{1}{ }^{*}$, Gurpreet Anand ${ }^{1}{ }^{*}$, Felix Beuschlein ${ }^{1,2}$

Affiliations

1 Klinik für Endokrinologie, Diabetologie und Klinische Ernährung, Universitätsspital Zürich, Zürich, Switzerland

2 Medizinische Klinik und Poliklinik IV, Klinikum der Universität München, Munich, Germany

\section{Key words}

pheochromocytoma, paraganglioma, primary aldosteronism, Cushing's syndrome, surgery, laparoscopy, perioperative management

$\begin{array}{ll}\text { received } & 13.05 .2018 \\ \text { revised } & 22.06 .2018 \\ \text { accepted } & 05.07 .2018\end{array}$

\section{Bibliography}

DOI https://doi.org/10.1055/a-0654-5251

Published online: 14.8.2018

Exp Clin Endocrinol Diabetes 2019; 127: 137-146

(C) J. A. Barth Verlag in Georg Thieme Verlag KG Stuttgart .

New York

ISSN 0947-7349

\section{Correspondence}

Prof. Felix Beuschlein, M.D.

Klinik für Endokrinologie, Diabetologie und Klinische

Ernährung

Universitätsspital Zürich

Rämistrasse 100

$\mathrm{CH}-8091$ Zürich

Switzerland

Tel.: +41/44/25536 25, Fax: +41/44/2553330

felix.beuschlein@usz.ch

\section{ABSTRACT}

Endocrine active adrenal tumors are associated with a relevant risk of complications during surgery, either due to direct hemodynamic effects of the hormone excess or due to hormone related comorbidities. Over the last decades, careful preoperative evaluation and improved peri-interventional medical management of affected patients has resulted in a significant reduction of perioperative complications. In addition, improvement in anesthesia and surgical techniques with the feasibility of laparoscopic adrenalectomy have contributed to reduce morbidity. Nevertheless, there are still several challenges to be considered in the perioperative care of these patients. Due to the rarity of functionally active adrenal tumors, there are no prospective data available to guide clinical management. Accordingly, most recommendations are based on retrospective data analysis, expert opinion or carry weak evidence based on small series or case reports. The aim of this review is to summarize the current knowledge and to suggest practical approaches to reduce perioperative complications in endocrine active adrenal tumors. This review exclusively deals with data from adult patients with functionally active adrenal tumors.

$\begin{array}{ll}\text { Abbreviations } \\ \text { PGL } & \text { paraganglioma } \\ \text { PCC } & \text { pheochromocytoma } \\ \text { PPGL } & \text { pheochromocytoma and paraganglioma } \\ \text { PA } & \text { primary aldosteronism } \\ \text { APA } & \text { aldosterone producing adenoma } \\ \text { CS } & \text { Cushing syndrome } \\ \text { BAH } & \text { bilateral adrenal hyperplasia } \\ \text { HPA axis } & \text { hypothalamic-pituitary-adrenal axis } \\ \text { ACC } & \text { adrenocortical carcinoma }\end{array}$

* Both authors contributed equally to the manuscript.

\section{Pheochromocytoma and paraganglioma (PCC and PGL)}

\section{Background}

Pheochromocytoma (PCC) are neuroendocrine tumors of chromaffin tissue mostly producing one or more catecholamines; epinephrine, norepinephrine and/or dopamine. Most PCC are intra-adrenal (90\%). Rarely, extra-adrenal PCC can be found in the paraganglia cells of the sympathetic nervous system, and the organ of Zuckerkandl. [1] Most PCC are endocrine active. On the other hand, paraganglioma (PGL) are tumors arising from parasympathetic or sympathetic ganglia which depending upon location may or may not be function- 
ally active. PGL arising from parasympathetic ganglia in the head and neck was previously thought to be non-functional. [2] However, the current literature has revealed that up to one third of head and neck PGL are, in fact hormonally active. [3] Sympathetic PGLs are commonly located around the inferior mesenteric artery or aortic bifurcation and are almost universally endocrine active.

Overall, PPGL represent tumors that carry a high risk of morbidity, even if benign. Further, these tumors (particularly PGL) carry a relevant risk of malignancy which requires long-term follow-up examinations. The major cause of morbidity results from hypersecretion of catecholamines, which may lead to hypertensive crisis, ventricular arrhythmia, myocardial infarction, stroke or other vascular manifestations. [2] In a retrospective study by Riester et al., patients with PCC were analyzed for incidence of life-threatening complications in three German centers from 2003 to 2012, whereby higher preoperative systolic blood pressure and the maximum tumor diameter were identified as predictors of life-threatening events. [4] The treatment of choice for PCC is laparoscopic adrenalectomy. [5] Surgical resection can be complicated by abrupt release of catecholamines during the induction of anesthesia or surgical manipulation of tumor leading to cardiovascular complications. From a physiological point-of-view, different adrenoreceptors are targeted differentially by catecholamines. Therapeutically, preoperative treatment with alpha-adrenergic receptor blockers to counteract their vasoconstrictive action has been shown to reduce the risk of perioperative cardiovascular complications in PPGL patients. Therefore, preoperative medical blockade has been recommended in current guidelines. [6]

\section{Preoperative management}

The catecholamine secretory profile depends on the localization of tumor (adrenal versus extra-adrenal) and underlying hereditary disease with a known germline mutation. Whereas PCC can produce any catecholamine, PGL mostly secrete norepinephrine or dopamine because of lack of expression of phenylethanolamin $\mathrm{N}$ methyltransferase necessary to convert norepinephrine to epinephrine. [7-8]

Clinical presentation of the patient may vary depending on catecholamine secretory profile due to differential receptor activation by different catecholamines.[7, 8] For example, adrenalin-secreting tumors may not only present with paroxysmal hypertension, but also hypotension whereas noradrenalin-secreting tumors more often result in persistent hypertension. Patients with dopaminesecreting tumors may have rather unstable blood pressure and may present with tachycardia. [9] Up to $50 \%$ of PCC may even be clinically asymptomatic, particularly in case of an adrenal incidentaloma implying the need of biochemical testing even in the absence of hypertension in this subgroup of patients. [7-8]

The Endocrine Society guidelines do not provide detailed recommendations for the extent of preoperative cardiological assessment of PPGL patients. Some authors consider preoperative cardiological evaluation to screen for cardiomyopathy or coronary heart disease, [10], while others postulate an individual approach depending on the risk constellation. [11] Other authors suggest a routine preoperative echocardiography to exclude a rare case of primary cardiac PPGL. [12] We suggest preoperative echocardiography in symptomatic patients and in patients with long-standing arterial hypertension to evaluate the extent of left ventricular dysfunction or indirect evidence of coronary heart disease.

\section{Preoperative medical treatment}

Alpha-adrenergic receptor antagonists In the current Clinical Practice Guideline of the Endocrine Society preoperative blockade with alpha-adrenergic receptor blockers is recommended in all patients with functionally active PPGL. The goal of preoperative medication is to normalize blood pressure and heart rate. After initiation of treatment with alpha-adrenergic receptor blockers, patients should be instructed to increase dietary sodium and fluid intake to reverse catecholamine-induced intravascular volume contraction. These measures can aid to decrease intraoperative hemodynamic instability and postoperative hypotension. [6]

The role of alpha-adrenergic receptor blockers in reducing perioperative cardiovascular complications has been suggested in many case series. Goldstein et al. observed a high perioperative complication rate of $69 \%$ in patients who did not receive alphablockers in a case series of 104 patients from 1950 to 1998. [13] Livingstone and coworkers reported an improved postoperative outcome in a retrospective review of PCC resection from 1992 to 2013 in 88 patients. This impressive reduction of perioperative morbidity from $40 \%$ to $7 \%$ was evident over the last 10 years of the study period and was mainly attributed to preoperative treatment with alpha-adrenergic receptor blockers. In particular, higher dosages of preoperatively administered alpha-adrenergic receptor blockers correlated with a reduction in the risk of hemodynamic instability. [14]

There has been some controversy in the literature regarding the need to use preoperative alpha-blockade in patients with atypical presentation. These patients with atypical presentation are characterized by normal or even low blood pressure despite biochemical evidence of a functionally active PPGL and/or have a predominant dopamine-secreting profile. These patients may not tolerate preoperative alpha-blockade very well and may have a higher risk of postoperative hypotension. However, if untreated, these patients have an increased risk of abrupt and extensive release of catecholamines provoking a hypertensive crisis or ventricular arrhythmias during tumor manipulation or induction of anesthesia, as several case studies have shown. $[15,16]$ Therefore, the risk of possible side-effects of preoperative alpha-blockade needs to be carefully weighed against the risk of perioperative hypertensive derailment in untreated patients. However, Lafont et al. could not find any difference in intraoperative hemodyamic instability in patients with normotensive and hypertensive PCC treated with alpha-adrenergic receptor blockers in their retrospective study from 2004 to 2012. Endocrine Guidelines suggest use of preoperative alpha-adrenergic receptor blockers in all functionally active PPGL as the benefit of reducing perioperative risk seems to clearly outweigh the possible side effects of the therapy. However, it should be noted that the side effects of medication can indeed be more pronounced in normotensive patients implying the need of careful dose-titration. [17] The last dose of alpha-adrenergic receptor blocker (phenoxybenzamine) is administered at our institution the evening before the operation and the morning dose is waived on the day of the operation to minimize postoperative hypotension. 
Although there are no prospective studies on the treatment of choice in premedication of PPGL patients, the Endocrine Society suggests alpha-adrenergic receptor blocker as the first choice based on the available retrospective data. [6] There is no clear drug preference for nonselective versus selective alpha-adrenergic receptor blockers due to lack of randomized controlled studies directly comparing effectiveness and limited international availability of all drugs. Phenoxybenzamine is used most frequently as a long-lasting, nonselective, and irreversible inhibitor of alpha- 1 and alpha-2 adrenoceptors. It may potentially lead to hypotension after tumor resection due to its long-lasting effect. [11] Current Endocrine Society guidelines suggest titration of phenoxybenzamine dose based on blood pressure. [6] In a retrospective study of 100 pheochromocytoma patients from 1992 to 2013, Livingstone reported median preoperative dose of phenoxybenzamine to be $119 \mathrm{mg}$ with a trend to use higher dosages in later years of the study. In this study, higher preoperative phenoxybenzamine doses were a significant predictor of improved intraoperative hemodynamic stability. [14] At our institution we usually begin with a starting dose of $5 \mathrm{mg} /$ day in the evening and increase it by $5-15 \mathrm{mg}$ per day till the aim is achieved or intolerable side-effects occur. The aim is to achieve normal hemodynamic parameters (blood pressure and pulse) with tolerable side effects (nasal congestion, orthostatic hypotension, diarrhea, dizziness and reflex tachycardia).

Selective and competitive alpha- 1 adrenoreceptor blockers such as prazosin, terazosin, and doxazosin are characterized by a shorter half-life. Some retrospective studies have reported fewer side effects, especially reflex tachycardia and postoperative hypotension, with selective alpha-1 adrenoreceptor blockers. [11, 18] However, a study by Kocak et al. could not find any significant difference in hemodynamic parameters intra- and postoperatively among phenoxybenzamine, doxazosin and prazosin. [19] In a further retrospective study on laparoscopic resection of PCCs, Weingarten and co-authors compared 50 Mayo Clinic patients (98\% received nonselective alpha- adrenoreceptor blocker, phenoxybenzamine) with 37 Cleveland patients (65\% received selective alpha- 1 adrenoreceptor blocker). In this study, patients premedicated with selective alpha- 1 adrenoreceptor blocker had significantly higher average blood pressure and required more volume (crystalloids and colloids) intraoperatively, whereas patients treated with nonselective alpha- 1 adrenoreceptor blocker required more phenylephrine to manage hypotension during surgery. The authors postulated a more efficient volume repletion under phenoxybenzamine reducing the need of volume replacement. However, there were no significant differences in postoperative outcome or duration of hospitalization. [20]

Therapeutic goals According to the current guidelines of the Endocrine society a duration of 7 to 14 days of preoperative treatment with alpha-adrenoreceptor blocker is suggested. The therapeutic goal is to achieve blood pressure levels of $<130 / 80 \mathrm{mmHg}$ in a seated position and a systolic blood pressure of $>90 \mathrm{mmHg}$ upon standing. The optimal heart rate is regarded to be between 60-70 beats/minute when sitting and between 70-80/minute when standing. As mentioned above, salt-rich diet and sufficient fluid intake are recommended preoperatively to reverse catecholamineinduced blood volume contraction. [6]
Beta-adrenergic receptor antagonists Beta blockers can be recommended as add-on treatment to combat reflex tachycardia. It is important to note that beta-adrenoreceptor blockers are only indicated after treatment with alpha-adrenoreceptor blockers is already established because of the danger of inducing hypertensive crisis due to unopposed alpha-adrenoreceptor activation through catecholamine excess in untreated patients. [6] According to Pacak, preference should be given to cardioselective beta-adrenoreceptor blockers, whereas the Endocrine Society does not provide any preference for nonselective versus selective beta-adrenoreceptor blockers. There is, however, a consensus to avoid treatment with a combined alpha- and betablocker (labetalol) due to the risk of paradoxical hypertension or hypertensive crises owing to its weaker alpha-antagonist action and stronger beta-antagonist action. $[6,11]$

Calcium-channel-blockers If the target blood pressure values are not reached with alpha-adrenoreceptor blocker, therapy can usually be expanded with calcium-channel-blockers. [6, 11] Some authors even propagate monotherapy with calcium-channel-blockers. [21-23] In our opinion, this should be considered as an option only in cases of mild hypertension or in patients suffering severe postural hypotension under treatment with alpha-adrenoreceptor blocker. [6]

Other agents Another therapeutic approach in preoperative medication is alpha-methyl-paratyrosine (metyrosine), a catecholamine synthesis inhibitor, in combination with alpha-adrenergic receptor blocker. There are few retrospective case studies suggesting a benefit in patients with more pronounced catecholamine release and a known metastatic disease. [24, 25] Wachtel et al. compared intraoperative hemodynamics in 174 PPGL patients $(81.6 \%$ were treated with phenoxybenzamine in combination with metyrosine while the remaining were treated with phenoxybenzamine alone). The authors reported less intraoperative hemodynamic instability and less postoperative cardiovascular complications in the combined treatment group.[26] Nonetheless, limited availability and intolerable side effects of metyrosine (sedation, depression, galactorrhea and extrapyramidal symptoms) caused by central and peripheral inhibition of catecholamine synthesis prohibit wider use of this agent. [11]

If hypertensive derailment occurs despite preoperative medication, sodium nitroprusside, nitroglycerine, phentolamine or urapidil can be used intraoperatively to control blood pressure. Tachyarrhythmias can usually be treated with short-acting beta-blockers and lidocaine. [1] Some drugs such as dopamine D2 receptor antagonists, opioid analgesics, norepinephrine reuptake inhibitors, serotonin reuptake inhibitors, monoamine oxidase inhibitors, corticosteroids, peptides, neuromuscular blocking agents, and beta-blockers without prior alpha-blockade can predispose the patient to hypertensive crisis. Accordingly, these drugs should be avoided. [6]

\section{Surgical management}

The standard treatment of PPGLs is surgical resection. Regarding surgical approach there are only retrospective analyses of patient data comparing laparoscopic with conventional transabdominal approach. However, in the recent literature the laparoscopic approach is clearly preferred over the transabdominal procedure due to many advantages such as reduced period of hospitalization, 
shorter recovery time, less blood loss, less postoperative pain, and less surgical morbidity. [5, 27-29]

Fernandez-Cruz and coworkers compared laparoscopic and transabdominal adrenalectomy and reported more cardiovascular instability following the transabdominal approach despite similar increases in intraoperative catecholamine levels. [27] On the other hand, Weisman et al. found no significant difference in hemodynamic instability between minimally invasive and open access. [5]

Gumbs and Gagner compiled 2565 cases of laparoscopic adrenalectomies for adrenal tumors. The authors reported the lateral transabdominal adrenalectomy as the most commonly performed procedure, followed by posterior retroperitoneal endoscopic adrenalectomy and laparoscopic anterior trans-abdominal adrenalectomy. Overall, the most frequent complications were postoperative bleeding ( $40 \%$ ), organ injuries (5\%), and wound infections. Interestingly, cardiovascular complications resulting from hypertensive crises were documented in only $1 \%$ of cases. There were no differences between the different laparoscopic approaches in terms of duration of hospital stay or complications. The only limiting factor to retroperitoneal access was maximum tumor size of 6-9cm. [30] According to a more recent retrospective study by Lee et al. comparing surgical access in 58 patients with adrenalectomy for adrenal tumors no relevant complications had occurred. [31] The Endocrine Society suggests to give priority to the retroperitoneal approach in patients who have previously undergone abdominal operations or those requiring a bilateral adrenalectomy. For patients with bilateral pheochromocytoma, Castillo et al. reported laparoscopic synchronous bilateral adrenalectomy to be a safe procedure.[32] Partial adrenalectomy is recommended in patients with bilateral disease or patients with hereditary PCC with a prior unilateral adrenalectomy to prevent postoperative adrenal insufficiency. [6] The negative corollary, of course, is the higher risk of recurrence in the adrenal-sparing approach. Asari and coworkers reviewed 348 patients with PCC due to MEN 2A. Following adrenal-sparing operation, $31 \%$ of 187 patients had a recurrent PCC (ipsi- or contralateral). In comparison, only 3\% of 161 patients undergoing bilateral complete adrenalectomy had a recurrent $\mathrm{PCC}$. [33]

In very large tumors and in tumors with apparent malignant potential, an open resection should be discussed to reduce the risk of intraoperative tumor rupture and to maximize the chances of complete resection. [30] According to the Endocrine Society guidelines, open surgery is recommended in tumor masses $>6 \mathrm{~cm}$. However, in 2006 Gumbs and Gagner suggested that laparoscopic adrenalectomy may be considered for the resection of benign secreting and non-secreting tumors up to $12 \mathrm{~cm}$. [30,34]

Great care must be taken to avoid tumor rupture during removal of pheochromocytoma. Rafat et al. reported 5 cases of tumor recurrence or persistence which showed evidence of tumor capsule rupture upon macroscopic examination of the surgical specimen. Indeed, peritoneal tumor implantation due to tumor capsule rupture during the resection of an apparently benign primary tumor, is a rare, but potentially disastrous complication leading to tumor persistence or recurrence. [35]

We suggest discussion of PPGL cases in interdisciplinary tumor boards to decide the best surgical approach for the individual patient. Due to increased risk of hemodynamic instability in patients with PPGL und technically challenging surgical removal of these highly vascular tumors, all surgeries should be preferably done in a tertiary care center with an experienced team of surgeons, anesthesiologists and endocrinologists to maximize chances of a successful outcome.

For detailed information for the choice of anesthetic agents and anesthesia techniques, we refer the reader to consult the relevant literature in the field. [36]

\section{Postoperative management}

Postoperatively, the Endocrine Society recommends close monitoring of blood pressure, heart rate and plasma glucose during the first $24-48 \mathrm{~h}$. There is a risk of postoperative hypotension due to longlasting effect of alpha adrenoreceptor blocker after surgical removal of the source of catecholamine excess. [1] However, persistent hypertension can also occur due to various causes such as excessive intraoperative fluid administration, residual tumor or unwanted ligation of the renal artery. Therefore, adjustment of medical treatment in the immediate postoperative period is likely to be required based on blood pressure and general clinical parameter. [1]

There are only individual case reports of postoperative hypoglycemia after removal of a PPGL, so that no statement on its exact prevalence is possible. However, some case reports reported severe symptomatic hypoglycemia grade II-III, which led to delayed awakening from anesthesia or occurred $30 \mathrm{~min}$ to $2 \mathrm{~h}$ postoperatively. A possible cause for this seems to be rebound hyperinsulinemia after surgical correction of catecholamine excess. Another potential mechanism could be an increased glucose uptake in peripheral tissues. [37, 38] Following complete or partial bilateral adrenalectomy or unilateral partial adrenalectomy of a single remaining adrenal gland, attention should be paid to the possibility of adrenal insufficiency. [6]

\section{Postoperative follow-up}

According to the European Endocrine Society guidelines, biochemical screening should be undertaken by measuring either plasma metanephrines or urinary levels of metanephrines and 3-methoxytyramine in a properly collected 24-h urine sample ideally 2-6 weeks after surgery to confirm complete PPGL resection. Certain risk factors such as young age, underlying genetic disease, and larger tumor size may predict higher risk of recurrence. [39] These highrisk patients should undergo lifelong annual screening to enable early detection of recurrent disease (local or metastatic) as well as new tumors. In our opinion, the possibility of genetic screening should be discussed with all patients. Especially, patients with other symptoms of hereditary disease, positive family history or known genetic mutation, immunohistochemical evidence of an underlying SDH-mutation in surgical specimen, bilateral disease and young age should be strongly advised to undergo genetic testing. Patients with sporadic tumors should be checked annually for a duration of at least 10 years according to the recent European Endocrine Society guidelines. [39] In addition, we suggest to instruct patients to actively report specific symptoms (worsening arterial hypertension, palpitations, increased sweating), thus allowing for symptombased detection of a recurrence which should be confirmed or refuted with a biochemical screening. Interfering medication should be suspended before undertaking biochemical screening. Patients 
- Table 1 Perioperative management of secreting adrenal tumors, adapted according to the guidelines of the Endocrine Society.

\begin{tabular}{|c|c|c|c|}
\hline & PCC & PA & CS \\
\hline $\begin{array}{l}\text { Preoperative } \\
\text { evaluation }\end{array}$ & $\begin{array}{l}\text { ECG, physical examination } \\
\text { Screening for metastatic tumors in } \\
\text { patients with PPGL, patients with PCC } \\
\text { and elevated 3-Methoxytyramine (3-MT) } \\
\text { in plasma or urine and in patients with } \\
\text { SDHB gene. }\end{array}$ & ECG, physical examination & $\begin{array}{l}\text { ECG, physical examination } \\
\text { Screen comorbidities: } \\
\text { - Hypertension } \\
\text { - Diabetes Dyslipidemia } \\
\text { - Osteoporosis } \\
\text { - Psychiatric diseases }\end{array}$ \\
\hline $\begin{array}{l}\text { Premedication and } \\
\text { immediate } \\
\text { postoperative care }\end{array}$ & $\begin{array}{l}\text { Alpha-adrenergic receptor antagonist } \\
\text { 7-14d before surgery } \\
\text { Thromboembolic prophylaxis }\end{array}$ & $\begin{array}{l}\text { Mineral corticoid receptor } \\
\text { antagonist until one week before } \\
\text { surgery } \\
\text { Thromboembolic prophylaxis }\end{array}$ & $\begin{array}{l}\text { Optimal treatment of comorbidities } \\
\text { Consider steroidogenesis inhibitors in cases of } \\
\text { florid CS } \\
\text { Antibiotic prophylaxis } \\
\text { Thromboembolic prophylaxis }\end{array}$ \\
\hline Therapeutic goals & $\begin{array}{l}\mathrm{BP}<130 / 80 \mathrm{mmHg} \\
\text { Heart rate } 60-70 \mathrm{bpm}\end{array}$ & $\begin{array}{l}\mathrm{BP}<140 / 90 \mathrm{mmHg} \\
\text { Normokalemia }\end{array}$ & $\begin{array}{l}\text { Aim for normal BP, normoglycemia and } \\
\text { normokalemia }\end{array}$ \\
\hline $\begin{array}{l}\text { Postoperative } \\
\text { period }\end{array}$ & $\begin{array}{l}\text { Monitoring of blood pressure, heart rate } \\
\text { and blood sugar for } 24-48 \mathrm{~h} \text { postopera- } \\
\text { tively }\end{array}$ & $\begin{array}{l}\text { Withdraw potassium substitution on } \\
\text { day } 1 \text { after surgery } \\
\text { Measurement of: } \\
\text { - renin } \\
\text { - aldosterone } \\
\text { - serum potassium } \\
\text { - serum creatinine }\end{array}$ & $\begin{array}{l}\text { Establish glucocorticoid substitution } \\
\text { Educate about the need of dose adjustment in } \\
\text { cases of stress } \\
\text { Measurement of morning cortisol } \\
\text { Thromboembolic prophylaxis up to 4-6 weeks } \\
\text { after surgery } \\
\text { Stop glucocorticoid substitution after recovery } \\
\text { of HPA axis; ACTH stimulation test }\end{array}$ \\
\hline $\begin{array}{l}\text { Common } \\
\text { complications }\end{array}$ & $\begin{array}{l}\text { Persistent hypertension } \\
\text { Hypotension } \\
\text { Hypoglycemia } \\
\text { Adrenal insufficiency (rare) }\end{array}$ & $\begin{array}{l}\text { Persistent hypertension } \\
\text { Hypotension } \\
\text { Hyperkalemia } \\
\text { Hypoaldosteronism } \\
\text { Adrenal insufficiency (rare) }\end{array}$ & $\begin{array}{l}\text { Thromboembolic complications up to } 1 \text { year } \\
\text { postoperative } \\
\text { Glucocorticoid withdrawal syndrome } \\
\text { Adrenal insufficiency (common) }\end{array}$ \\
\hline Follow-up & $\begin{array}{l}\text { Metanephrines in plasma or urine } 2-6 \\
\text { weeks postoperatively, then annually for } \\
10 \text { years } \\
\text { Lifelong screening in high-risk patients } \\
\text { (young patients, genetic disease, large } \\
\text { tumor and/or PPGL) }\end{array}$ & $\begin{array}{l}\text { BP control } \\
\text { Serum potassium, plasma } \\
\text { aldosterone and renin activity } \\
\text { postoperatively }\end{array}$ & Lifelong screening for comorbidities. \\
\hline
\end{tabular}

with biochemical evidence of recurrence require imaging studies for further evaluation.

For an overview on perioperative management, please refer to - Table 1.

\section{Primary Aldosteronism (PA)}

\section{Background and diagnosis}

Primary aldosteronism (PA) is the most common form of secondary arterial hypertension, even though currently underdiagnosed due to lack of awareness to screen patients at risk. The cardiovascular sequelae occur more frequently than in patients with essential hypertension, which is why early targeted therapy is essential. The prevalence of PA in hypertensive patients is estimated between $5-10 \%$ [40-42] with a correlation of the prevalence with the severity of arterial hypertension. [41,42] The most common causes of PA are adrenal adenoma (APA) and bilateral adrenal hyperplasia (BAH). Adrenal carcinoma or familial hyperaldosteronism are rare causes. [40, 43]

\section{Therapeutic approach}

Once the diagnosis of primary hyperaldosteronism is confirmed, the Endocrine Society guidelines recommend adrenal venous sampling in the majority of patients seeking surgical treatment options. How- ever, patients $<35$ years of age with pronounced PA (spontaneous hypokalemia, serum aldosterone $>30 \mathrm{ng} / \mathrm{dl}$ or $831 \mathrm{pmol} / \mathrm{I}$ ) and a corresponding unilateral adenoma on imaging can forego adrenal vein sampling as the probability of a functionally inactive adenoma is believed to be low in young patients. [40] The choice of therapy depends on the subtype of aldosterone excess. In a unilateral source of aldosterone excess (adrenal adenoma or unilateral adrenal hyperplasia), laparoscopic adrenalectomy is the best treatment. Patients suffering from BAH or inoperable patients with serious comorbidities should be treated medically with mineralocorticoid receptor antagonists. Spironolactone is the first- line agent, while eplerenone can be administered as an alternative if side effects occur (especially gynecomastia and erectile dysfunction in men and menstrual disturbances in premenopausal women). [40]

In a recent prospective study by Rossi and colleagues, long-term cardiovascular effects such as blood pressure control, left ventricular changes and the incidence of cardiovascular events (including atrial fibrillation) were investigated in 323 patients with hypertension. 180 patients had $\mathrm{PA}$, out of which 110 were adrenalectomized and 70 were treated with mineralocorticoid receptor antagonists, and compared to 143 patients with medically treated essential hypertension. Notably, patients with PA had significantly more left ventricular hypertrophy than patients with essential hypertension. After specific therapy (adrenalectomy or mineral corticoid receptor antagonists), patients with PA showed a regression of left ven- 
tricular changes comparable to patients with optimally treated essential hypertension. [44] These findings argue for the necessity of an early, specific therapy of PA.

\section{Preoperative management}

Preoperatively, blood pressure values and hypokalemia should be optimally adjusted preferably with a mineralocorticoid receptor antagonist according to the Endocrine Society Guideline. Mostly, a starting dose of $12.5 \mathrm{mg}-25 \mathrm{mg}$ spironolactone is used with titration up to a maximum dose of $100 \mathrm{mg}$. [40] However, there are no specific recommendations about the optimum duration of preoperative treatment. At our institution, we treat patients with spironolactone for a duration of 4-6 weeks to achieve a target blood pressure of $<140 / 90 \mathrm{mmHg}$ und normokalemia without potassium supplementation. Postoperatively, hypoaldosteronism may occur due to chronic suppression of the contralateral adrenal gland. Earlier, it was believed that preoperative spironolactone therapy may antagonize renin suppression and thus may prevent postoperative zona glomerulosa insufficiency, whereas Fischer et al. could not support this hypothesis on the basis of a retrospective analysis of 110 patients adrenalectomized for unilateral adenoma. [45] Based on our case-based experience, we suggest to discontinue spironolactone up to 1 week before surgery. The rationale for this approach is long half-life of active metabolites, even though the plasma half-life of spironolactone itself is short (1.3 h). Patients are maintained on other antihypertensives and or potassium substitution to maintain normotension and normokalemia till the day of surgery.

\section{Surgical management}

Laparoscopic adrenalectomy is the standard therapy for unilateral disease due to shorter hospitalization time, less blood loss, fewer complications and less need for analgesics. [46] In addition, the adrenal gland is not visibly enlarged in many cases of unilateral PA in contrast to other adrenal tumors such as PCC or Cushing adenomas. Mostly, total adrenalectomy is preferred over partial adrenalectomy to ensure remission. [40] Nanba et al. showed in a retrospective study of 55 patients following adrenalectomy in PA that three of the patients (5.5\%) did not experience postoperative improvement despite preoperative lateralization by adrenal vein sampling. All 3 patients had a partial adrenalectomy, whereas all patients with total adrenalectomy were cured postoperatively. [47] In a study by Pautler et al. on 11 patients with laparoscopic partial adrenalectomy, intraoperative ultrasound was used to improve the differentiation between adrenal parenchyma and tumor tissue to optimize the outcome of partial adrenalectomy. The authors were able to detect an additional lesion in one patient that was not seen in preoperative imaging. [48] However, whether these lesions correspond to endocrine active nodules remains uncertain. In general, surgical treatment has been shown to be cost-effective as compared to lifelong medical therapy in unilateral disease. [49-50]

\section{Postoperative management}

In a retrospective study, Kim et al. compared 26 PCC patients with 34 patients with PA who had laparoscopic adrenalectomy. As expected, tumor size, surgery duration and cardiovascular complication rates were higher for PCC than APA patients. [51] The possible postoperative complications (postoperative bleeding, wound infection, pain) were comparable among those groups.

A slight creatinine increase is not uncommon after unilateral adrenalectomy in PA patients. Vasodilatation of the arterioles and increased sodium reabsorption via tubulo-glomerular feedback leads to glomerular hyperfiltration and thus often masks a restricted kidney function. [45] Furthermore, structural changes of the renal parenchyma are observed in the context of PA, which could be explained by the long-standing arterial hypertension as well as by direct toxic effects of aldosterone. [45, 52] A detailed analysis of the German Conn's Registry patients in 2009 revealed a moderate postoperative decline in glomerular filtration rate, which stabilized in the long-term follow-up. [53]

In severe cases, unilateral aldosterone excess can result in complete suppression of the contralateral zona glomerulosa; as a result, potassium substitution and mineralocorticoid receptor antagonists must be suspended postoperatively and electrolyte checks should be carried out regularly. Fischer et al. showed in a retrospective chart review of 110 patients adrenalectomized for unilateral adenoma that $16 \%$ of patients had postoperative hyperkalemia due to prolonged zona glomerulosa insufficiency. $5 \%$ of patients even required mineralocorticoid therapy for 11-46 months. Predictive markers for development of postoperative hyperkalemia were reduced glomerular filtration rate before operation which worsened further after operation and microalbuminuria. [45]

Recently, based on a multi-steroid analysis, it has been demonstrated, that a subgroup of PA patients are characterized by a cosecretion of glucocorticoids. Although, these patients did not display obvious clinical manifestations of Cushing's syndrome within this cohort, a number of metabolic parameters such as BMI, waist circumference and and HOMA-IR were well correlated with total glucocorticoid output. Following surgery for unilateral PA, elevated cortisol levels returned to normal and 13 out of 45 patients (29\%) failed a co-syntropin test indicating partial adrenal insufficiency. [54] In light of this recent evidence, we suggest to perform low-dose overnight dexamethasone-suppression test to evaluate cortisol co-secretion in PA patients. In case of a pathological result, these patients should be carefully monitored during immediate postoperative period to rule out postoperative adrenal insufficiency and to provide hydrocortisone substitution as a stress dosage.

\section{Follow-up}

Blood pressure can be expected to improve or normalize within the first 1-6 months after successful surgery. [40] Based on an international retrospective analysis of 705 patients from 12 different centers (The Primary Aldosteronism Surgical Outcome study, PASO), standardized criteria for postoperative outcome with regard to clinical and biochemical response were defined. According to the PASO consensus, blood pressure and serum potassium should be determined within the first 3 months postoperatively for optimal adaptation of antihypertensive therapy and any necessary potassium substitution. Within the first 6-12 months after adrenalectomy, blood pressure, serum potassium, aldosterone and renin should be measured again for a final assessment of therapy success. Subsequently, follow-up should be carried out annually to evaluate longterm blood pressure control and to assess general cardiovascular risk profiles. Evidence on recurrence of primary aldosteronism fol- 
lowing surgery is sparse but should be considered in patients with worsening of blood pressure control or development of hypokalemia. According to the PASO study, complete clinical remission of $37 \%$ and a partial clinical success rate of $47 \%$ after surgery can be expected. Biochemically, the success rate was significantly higher at $94 \%$. Clinical outcome was significantly better in younger and female patients than in older and male patients or in patients with comorbidities especially OSAS and diabetes. [55]

For an overview on perioperative management, please refer to - Table 1.

\section{Cushing's Syndrome (CS)}

\section{Background}

Cushing's syndrome (CS) is a rare endocrine disorder characterized by either ACTH-dependent (caused by a pituitary tumor or ectopic ACTH-production) or ACTH-independent (adrenal tumor) hypercortisolism. The most common cause is pituitary adenoma, followed by adrenal adenoma. Adrenocortical carcinoma (ACC) and malignant ectopic ACTH overproduction are rare causes, but accompanied by a poor prognosis. [56] In a retrospective study by Lindholm et al., the incidence of pituitary Cushing's disease was reported at 1.2-1.7/million/yr. For adrenal adenoma, an incidence of $0.6 /$ million/yr. and for adrenal carcinoma $0.2 /$ million/yr. has been estimated. [57]

Clinically, the patient with cortisol excess may present with a plethora of symptoms such as visceral obesity, proximal myopathy, alopecia, hirsutism, abdominal striae rubrae and easy bruising (ecchymosis). The predominant comorbidities are obesity, insulin resistance, arterial hypertension and dyslipidemia. Furthermore, steroid induced immunodeficiency can develop, which significantly increases the risk of opportunistic infections. In addition, osteoporosis and psychiatric diseases, in particular depression, restricted cognitive function and psychosis also occur more frequently. [58]

The treatment of choice is early removal of the lesion causing hormone excess. If this cannot be achieved (in case of extensive pituitary surgery or in occult ectopic ACTH production) bilateral adrenalectomy can be performed to normalize hypercortisolism. $[56,59]$ Overall, in patients with Cushing's syndrome, a benign adrenal cortisol producing adenoma offers best chances of cure.

\section{Preoperative management}

The optimal treatment of comorbidities associated with cortisol excess is essential in the perioperative management and for the postoperative long-term course of CS. In particular, blood glucose control using antidiabetic medication and/or insulin therapy as well as blood pressure control should be optimized. Patients should be screened for dyslipidemia and treated accordingly. The treatment of possible secondary psychiatric diseases is unfortunately often overlooked, but it should not be neglected. Patients with electrolyte abnormalities, especially hypokalemia, need appropriate substitution before operation. Due to the increased risk of infection, vaccination for influenza, herpes zoster and pneumococcus are recommended before surgery.[56] Signs and symptoms of an underlying infection may be masked in a state of cortisol excess due to immunosuppressive effect of glucocorticoids. It is important to remain vigilant about the possibility of infection following adrenalectomy. There are some case reports of life-threatening postoperative infection (especially pneumocystis jiroveci). [60] The Endocrine Society does not make any precise recommendations, but points to the possibility of a prophylactic administration of trimethoprim-sulfamethoxazole to prevent Pneumocystis jiroveci infections. [56] Alternatively, an extended perioperative antibiotic prophylaxis may be evaluated.

Another potentially life-threatening complication of CS is venous thromboembolism, which makes perioperative thromboembolic prophylaxis mandatory. [56] This risk seems to be lower in patients with benign adrenal tumor as a cause of CS. In a retrospective multicenter cohort study of 473 patients, 360 of whom had ACTH-dependent pituitary CS, Stuijver et al. found a postoperative incidence rate of $3.4 \%$ in these patients within the first 3 months following surgery. However, in this study no patient with $\mathrm{ACTH}$-independent hypercortisolism suffered a thromboembolic event within 3 months. [61] In an analysis of 8 studies on 476 patients with Cushing's syndrome from Van Zaane et al., 78 patients with adrenal hypercortisolism and 398 patients with ACTH-dependent hypercortisolism had a postoperative risk of thromboembolism between 0.5 and 5.6\%. [62] Koutroumpi et al. identified increased urinary cortisol excretion and increased levels of von Willebrand factor as predictive markers based on retrospective analysis of 108 patients with CS, 58 of whom suffered from thromboembolism. [63] There are no prospective data on the dosage and duration of thromboprophylaxis available in the literature. Nevertheless, preoperative and prolonged postoperative prophylaxis, at least during the 4-6 weeks after surgery, in addition to early mobilization are recommended. [64-65]

Another aspect that should not be neglected in the preoperative evaluation of Cushing's patients is proximal myopathy, which significantly impairs the quality of life. In a retrospective study by Berr et al. in which 47 patients with CS were compared with 149 in remission after CS and 93 control patients, it was shown that myopathy is relevant in both the florid stage and in long-term observation. [66] These patients may benefit from the ongoing intensive muscle training in the long-term postoperative course.

\section{Surgical management}

As already mentioned, the surgical procedure of choice is laparoscopic adrenalectomy in case of adrenal CS. This is also increasingly carried out in ACC, although many cases still require conventional transabdominal approach. [56] As the precise surgical strategies to approach ACC is beyond the scope of this overview we refer to a recent review by Rayes et al. on this topic. [67]

\section{Postoperative management}

Due to previous hypercortisolism, the hypothalamic-pituitary-adrenal axis is suppressed, which is why immediate postoperative glucocorticoid substitution is necessary. The Endocrine Society recommends a glucocorticoid substitution of $10-12 \mathrm{mg} / \mathrm{m}^{2}$ per day in 2-3 daily doses. To assess the success of surgery serum cortisol and ACTH should be measured. According to the Endocrine Society, remission of hypercortisolism is defined as morning serum cortisol levels $<5 \mu \mathrm{g} / \mathrm{dL}(<138 \mathrm{nmol} / \mathrm{L})$ or UFC $<28-56 \mathrm{nmol} / \mathrm{d}$ 
$(<10-20 \mu \mathrm{g} / \mathrm{d}) 7$ days after surgery. [56] To avoid interference with substitution therapy, hydrocortisone needs to be paused for the evaluation. In patients with a high likelihood of adrenal insufficiency measurement of morning serum cortisol with the last dosage of hydrocortisone at the afternoon of the previous day seems more appropriate than longer discontinuation for urine sampling. Usually the function of the HPA axis recovers within the first 18 months after unilateral adrenalectomy. A retrospective analysis by Berr et al. of 91 patients with 3 different subtypes of CS (Cushing's disease, adrenal CS and ectopic CS) also showed that the recovery of adrenal function depends on the etiology of the cortisol excess. [68] After bilateral adrenalectomy, there is a lifelong need for glucocorticoid and mineralocorticoid replacement. All patients must be informed preoperatively about adrenal insufficiency and instructed postoperatively on the adequate adjustment of the glucocorticoid dose in case of stress or infections. The postoperative dose adjustment should be undertaken by an endocrinologist. Every patient should receive an internationally valid emergency card implying the need of glucocorticoid treatment in emergency situations. [56]

After surgical correction of hypercortisolism, patients often suffer from symptoms of hormone withdrawal. Within the first postoperative days, this may lead to fatigue, nausea, somnolence, fever and joint pain and are sometimes difficult to delineate from symptoms of an Addison crisis. Biochemically, hypercalcemia and hyperphosphatemia can often be detected. The administration of a supraphysiologic hydrocortisone doses may reduce the symptoms; however, the dose should be reduced as quickly as possible to avoid iatrogenic CS. The symptoms of withdrawal can persist for up to a year postoperatively. [69]

Due to the proximal myopathy as described above, postoperative muscle-training and physiotherapy should be recommended. [66]

\section{Follow-up}

Postoperatively, a regular endocrine check-up should be ensured to evaluate and adapt the dose of substitution therapy. Glucocorticoid - and in cases of bilateral adrenalectomy mineralocorticoid - doses should mainly be based on clinical evaluation, blood pressure as well as serum potassium and plasma renin concentration. [56] The Endocrine Society does not recommend a specific scheme, but in our institution, we measure morning cortisol between 6:008:00 a.m on the first postoperative day while the patient is placed on dexamethasone-treatment $0.5 \mathrm{mg}$ every 6 - $\mathrm{h}$ after adrenalectomy. This low-dose dexamethasone does not interfere with the analysis of early morning cortisol as this is expected to be low in case of successful surgery. A morning cortisol $<50 \mathrm{nmol} / \mathrm{l}$ confirms successful removal of tumor. Then, we start treatment with hydrocortisone and monitor the patient clinically to adjust the hydrocortisone dose. The duration of hydrocortisone substitution can vary from patient to patient. We perform ACTH stimulation test $(08.00$ a.m) to assess recovery of HPA axis every 3 months until normalization (stimulated Cortisol $>441 \mathrm{nmol} / \mathrm{L}$ ). The last dose of hydrocortisone should be taken at least $18-24 \mathrm{~h}$. before blood examination. It should be mentioned that testing for adrenal insufficiency varies from institution to institution due to the lack of specific guidelines. [70]
Due to the comorbidities associated with hypercortisolism, mortality and morbidity in CS are significantly higher than in the normal population. Even 10 years after remission, overall mortality was significantly higher, especially due to cardiovascular diseases. [71] In a retrospective study of 253 patients with CS, Bolland and colleagues demonstrated that mortality and morbidity remained elevated despite biochemical remission of cortisol excess. After therapy, arterial hypertension, sexual dysfunction, myopathy and mild psychiatric diseases improved, whereas diabetes mellitus, severe psychiatric diseases and osteoporosis were still detectable years after treatment. [72] For this reason, regular postoperative follow-up and treatment of cardiovascular risk factors is indicated. [56] In addition, patients following resection of an adrenocortical carcinoma require long-term oncological/endocrine follow-up.

All patients with adrenal incidentaloma should be screened for autonomous cortisol secretion even though these patients mostly lack clinical signs or symptoms of Cushing's syndrome. As described above, patients with aldosterone producing adenomas can co-secrete cortisol. Because of important implication of impending adrenal insufficiency upon removal of these tumors, we suggest performing overnight dexamethasone-suppression test to evaluate cortisol oversecretion.

For an overview on perioperative management, please refer to ^ Table 1.

\section{Conclusion}

Depending on the secreted hormone, there are different perioperative risks associated with adrenal surgery, which can be minimized by optimal perioperative management. All cases should be discussed in interdisciplinary boards to offer best possible care and managed by an interdisciplinary team in a tertiary care center with sufficient experience.

Due to the rarity of these tumors, a prospective, randomized study is unlikely to be conducted, which is why we strongly encourage maintaining national registers and active participation in international networks such as the ENS@T database to further optimize patient outcomes.

\section{Conflict of Interest}

No conflict of interest has been declared by the authors.

\section{References}

[1] Kinney MA, Narr B], Warner MA. Perioperative management of pheochromocytoma. J Cardiothorac Vasc Anesth 2002; 16: 359-369

[2] Chen H, Sippel RS, O’Dorisio MS et al. The North American Neuroendocrine Tumor Society consensus guideline for the diagnosis and management of neuroendocrine tumors: Pheochromocytoma, paraganglioma, and medullary thyroid cancer. Pancreas 2010; 39: 775-783 doi:10.1097/MPA.0b013e3181ebb4f0

[3] van Duinen N, Corssmit EP, de Jong WH et al Plasma levels of free metanephrines and 3-methoxytyramine indicate a higher number of biochemically active HNPGL than 24-h urinary excretion rates of catecholamines and metabolites. Eur J Endocrinol 2013; 169: 377-382 doi:10.1530/EJE-13-0529 
[4] Riester A, Weismann D, Quinkler M et al. Life-threatening events in patients with pheochromocytoma. Eur J Endocrinol 2015; 173: 757-764 doi:10.1530/EJE-15-0483

[5] Weismann D, Fassnacht M, Weinberger $F$ et al. Intraoperative haemodynamic stability in patients with phaeochromocytoma--minimally invasive vs conventional open surgery. Clin Endocrinol (Oxf) 2006; 65: 352-358 doi:10.1111/j.1365-2265.2006.02603.x

[6] Lenders JW, Duh QY, Eisenhofer $G$ et al Pheochromocytoma and paraganglioma: an endocrine society clinical practice guideline. J Clin Endocrinol Metab 2014; 99: 1915-1942 doi:10.1210/jc.2014-1498

[7] Kopetschke R, Slisko M, Kilisli A et al. Frequent incidental discovery of phaeochromocytoma: Data from a German cohort of 201 phaeochromocytoma. Eur J Endocrinol 2009; 161: 355-361 doi:10.1530/EJE-09-0384

[8] Pacak K, Tella SH. Pheochromocytoma and Paraganglioma. In: De Groot LJ, Chrousos G, Dungan K et al. (eds). Endotext. South Dartmouth (MA): 2000

[9] Isaacs M, Lee P. Preoperative alpha-blockade in phaeochromocytoma and paraganglioma: Is it always necessary? Clin Endocrinol (Oxf) 2017; 86: 309-314 doi:10.1111/cen.13284

[10] Mannelli M. Management and treatment of pheochromocytomas and paragangliomas. Ann N Y Acad Sci 2006; 1073: 405-416 doi:10.1196/ annals. 1353.044

[11] Pacak K. Preoperative management of the pheochromocytoma patient. J Clin Endocrinol Metab 2007; 92: 4069-4079 doi:10.1210/ jc. $2007-1720$

[12] Osranek M, Bursi F, Gura GM et al. Echocardiographic features of pheochromocytoma of the heart. Am J Cardiol 2003; 91: 640-643

[13] Goldstein RE, O'Neill JA Jr., Holcomb GW 3rd et al. Clinical experience over 48 years with pheochromocytoma. Ann Surg 1999; 229: 755-764 discussion 764-756

[14] Livingstone M, Duttchen K, Thompson J et al. Hemodynamic Stability During Pheochromocytoma Resection: Lessons Learned Over the Last Two Decades. Ann Surg Oncol 2015; 22: 4175-4180 doi:10.1245/ s10434-015-4519-y

[15] Song G, Joe BN, Yeh BM et al. Risk of catecholamine crisis in patients undergoing resection of unsuspected pheochromocytoma. Int Braz J Urol 2011; 37: 35-40 discussion 40-31

[16] Kota SK, Kota SK, Panda S et al. Pheochromocytoma: an uncommon presentation of an asymptomatic and biochemically silent adrenal incidentaloma. Malays J Med Sci 2012; 19: 86-91

[17] Lafont M, Fagour C, Haissaguerre M et al. Per-operative hemodynamic instability in normotensive patients with incidentally discovered pheochromocytomas. J Clin Endocrinol Metab 2015; 100: 417-421 doi:10.1210/jc.2014-2998

[18] Prys-Roberts C, Farndon JR. Efficacy and safety of doxazosin for perioperative management of patients with pheochromocytoma. World J Surg 2002; 26: 1037-1042 doi:10.1007/s00268-002-6667-z

[19] Kocak S, Aydintug S, Canakci N. Alpha blockade in preoperative preparation of patients with pheochromocytomas. Int Surg 2002; 87: 191-194

[20] Weingarten TN, Cata JP, O'Hara JF et al. Comparison of two preoperative medical management strategies for laparoscopic resection of pheochromocytoma. Urology 2010; 76: 508 e506-508 e511 doi:10.1016/j.urology.2010.03.032

[21] Proye C, Thevenin D, Cecat P et al. Exclusive use of calcium channel blockers in preoperative and intraoperative control of pheochromocytomas: hemodynamics and free catecholamine assays in ten consecutive patients. Surgery 1989; 106: 1149-1154

[22] Combemale F, Carnaille B, Tavernier B et al. [Exclusive use of calcium channel blockers and cardioselective beta-blockers in the pre- and per-operative management of pheochromocytomas. 70 cases]. Ann Chir 1998; 52: 341-345
[23] Takahashi S, Nakai T, Fujiwara R et al. Effectiveness of long-acting nifedipine in pheochromocytoma. Jpn Heart J 1989; 30: 751-757

[24] Steinsapir J, Carr AA, Prisant LM et al. Metyrosine and pheochromocytoma. Arch Intern Med 1997; 157: 901-906

[25] Perry RR, Keiser HR, Norton JA et al. Surgical management of pheochromocytoma with the use of metyrosine. Ann Surg 1990; 212: 621-628

[26] Wachtel H, Kennedy EH, Zaheer S et al. Preoperative Metyrosine Improves Cardiovascular Outcomes for Patients Undergoing Surgery for Pheochromocytoma and Paraganglioma. Ann Surg Oncol 2015; 22: (Suppl 3): S646-S654 doi:10.1245/s10434-015-4862-z

[27] Fernandez-Cruz L, Taura P, Saenz A et al. Laparoscopic approach to pheochromocytoma: Hemodynamic changes and catecholamine secretion. World J Surg 1996; 20: 762-768 discussion 768

[28] Agarwal G, Sadacharan D, Aggarwal V et al. Surgical management of organ-contained unilateral pheochromocytoma: Comparative outcomes of laparoscopic and conventional open surgical procedures in a large single-institution series. Langenbecks Arch Surg 2012; 397: 1109-1116 doi:10.1007/s00423-011-0879-3

[29] Shen WT, Grogan R, Vriens M et al. One hundred two patients with pheochromocytoma treated at a single institution since the introduction of laparoscopic adrenalectomy. Arch Surg 2010; 145: 893-897 doi:10.1001/archsurg.2010.159

[30] Gumbs AA, Gagner M. Laparoscopic adrenalectomy. Best Pract Res Clin Endocrinol Metab 2006; 20: 483-499 doi:10.1016/j. beem.2006.07.010

[31] Lee CR, Walz MK, Park S et al. A comparative study of the transperitoneal and posterior retroperitoneal approaches for laparoscopic adrenalectomy for adrenal tumors. Ann Surg Oncol 2012; 19: 2629-2634 doi:0.1245/s10434-012-2352-0

[32] Castillo OA, Lopez-Fontana G, Vitagliano G. Laparoscoscopic synchronous bilateral adrenalectomy. Arch Esp Urol 2011; 64: 114-120

[33] Asari R, Scheuba C, Kaczirek K et al. Estimated risk of pheochromocytoma recurrence after adrenal-sparing surgery in patients with multiple endocrine neoplasia type 2 A. Arch Surg 2006; 141: 1199-1205 discussion 1205 doi:10.1001/archsurg.141.12.1199

[34] Shen WT, Sturgeon C, Clark OH et al Should pheochromocytoma size influence surgical approach? A comparison of 90 malignant and 60 benign pheochromocytomas. Surgery 2004; 136: 1129-1137 doi:10.1016/j.surg.2004.05.058

[35] Rafat C, Zinzindohoue F, Hernigou A et al. Peritoneal implantation of pheochromocytoma following tumor capsule rupture during surgery. J Clin Endocrinol Metab 2014; 99: E2681-E2685 doi:10.1210/ jc.2014-1975

[36] Li N, Kong H, Li SL et al. Combined epidural-general anesthesia was associated with lower risk of postoperative complications in patients undergoing open abdominal surgery for pheochromocytoma: A retrospective cohort study. PLoS One 2018; 13: e0192924 doi:10.1371/journal.pone.0192924

[37] Chambers S, Espiner EA, Donald RA et al. Hypoglycaemia following removal of phaeochromocytoma: Case report and review of the literature. Postgrad Med J 1982; 58: 503-506

[38] Meeke RI, O'Keeffe JD, Gaffney JD. Phaeochromocytoma removal and postoperative hypoglycaemia. Anaesthesia 1985; 40: 1093-1096

[39] Plouin PF, Amar L, Dekkers OM et al. European Society of Endocrinology Clinical Practice Guideline for long-term follow-up of patients operated on for a phaeochromocytoma or a paraganglioma. Eur ] Endocrinol 2016; 174: G1-G10 doi:10.1530/EJE-16-0033

[40] Funder JW, Carey RM, Mantero F et al. The Management of Primary Aldosteronism: Case Detection, Diagnosis, and Treatment: An Endocrine Society Clinical Practice Guideline. J Clin Endocrinol Metab 2016; 101: 1889-1916 doi:10.1210/jc.2015-4061 
[41] Hannemann A, Wallaschofski H. Prevalence of primary aldosteronism in patient's cohorts and in population-based studies - a review of the current literature. Horm Metab Res 2012; 44: 157-162 doi:10.1055/s-0031-1295438

[42] Rossi GP, Bernini G, Caliumi C et al. A prospective study of the prevalence of primary aldosteronism in 1,125 hypertensive patients. J Am Coll Cardiol 2006; 48: 2293-2300 doi:10.1016/j.jacc.2006.07.059

[43] Monticone S, D'Ascenzo F, Moretti C et al. Cardiovascular events and target organ damage in primary aldosteronism compared with essential hypertension: a systematic review and meta-analysis. Lancet Diabetes Endocrinol 2018; 6: 41-50 doi:10.1016/S22138587(17)30319-4

[44] Rossi GP, Cesari M, Cuspidi C et al. Long-term control of arterial hypertension and regression of left ventricular hypertrophy with treatment of primary aldosteronism. Hypertension 2013; 62: 62-69 doi:10.1161/HYPERTENSIONAHA. 113.01316

[45] Fischer E, Hanslik G, Pallauf A et al. Prolonged zona glomerulosa insufficiency causing hyperkalemia in primary aldosteronism after adrenalectomy. J Clin Endocrinol Metab 2012; 97: 3965-3973 doi:10.1210/jc.2012-2234

[46] Jacobsen NE, Campbell JB, Hobart MG. Laparoscopic versus open adrenalectomy for surgical adrenal disease. Can J Urol 2003; 10 : 1995-1999

[47] Nanba AT, Nanba K, Byrd JB et al. Discordance between imaging and immunohistochemistry in unilateral primary aldosteronism. Clin Endocrinol (Oxf) 2017; 87: 665-672 doi:10.1111/cen.13442

[48] Pautler SE, Choyke PL, Pavlovich CP et al. Intraoperative ultrasound aids in dissection during laparoscopic partial adrenalectomy. J Urol 2002; 168: 1352-1355 doi:10.1097/01.ju.0000031272.56889.28

[49] Reimel B, Zanocco K, Russo M] et al. The management of aldosteroneproducing adrenal adenomas--does adrenalectomy increase costs? Surgery 2010; 148: 1178-1185 discussion 1185 doi:10.1016/j. surg.2010.09.012

[50] Sywak M, Pasieka JL. Long-term follow-up and cost benefit of adrenalectomy in patients with primary hyperaldosteronism. $\mathrm{Br}$ J Surg 2002; 89: 1587-1593 doi:10.1046/j.1365-2168.2002.02261.x

[51] Kim AW, Quiros RM, Maxhimer JB et al. Outcome of laparoscopic adrenalectomy for pheochromocytomas vs aldosteronomas. Arch Surg 2004; 139: 526-529 discussion 529-531 doi:10.1001/archsurg.139.5.526

[52] Sechi LA, Colussi G, Di Fabio A et al. Cardiovascular and renal damage in primary aldosteronism: Outcomes after treatment. Am J Hypertens 2010; 23: 1253-1260 doi:10.1038/ajh.2010.169

[53] Reincke M, Rump LC, Quinkler M et al. Risk factors associated with a low glomerular filtration rate in primary aldosteronism. J Clin Endocrinol Metab 2009; 94: 869-875 doi:10.1210/jc.2008-1851

[54] Arlt W, Lang K, Sitch AJ et al. Steroid metabolome analysis reveals prevalent glucocorticoid excess in primary aldosteronism. JCI Insight 2017; 2: doi:10.1172/jci.insight.93136

[55] Williams TA, Lenders JWM, Mulatero $P$ et al Outcomes after adrenalectomy for unilateral primary aldosteronism: an international consensus on outcome measures and analysis of remission rates in an international cohort. Lancet Diabetes Endocrinol 2017; 5: 689-699 doi:10.1016/S2213-8587(17)30135-3

[56] Nieman LK, Biller BM, Findling JW et al. Treatment of Cushing's Syndrome: An Endocrine Society Clinical Practice Guideline. J Clin Endocrinol Metab 2015; 100: 2807-2831 doi:10.1210/jc.2015-1818
[57] Lindholm J, Juul S, Jorgensen JO et al. Incidence and late prognosis of cushing's syndrome: A population-based study. J Clin Endocrinol Metab 2001; 86: 117-123 doi:10.1210/jcem.86.1.7093

[58] Pivonello R, Isidori AM, De Martino MC et al. Complications of Cushing's syndrome: State of the art. Lancet Diabetes Endocrinol 2016; 4: 611-629 doi:10.1016/S2213-8587(16)00086-3

[59] Porterfield JR, Thompson GB, Young WF Jr. et al. Surgery for Cushing's syndrome: An historical review and recent ten-year experience. World J Surg 2008; 32: 659-677 doi:10.1007/s00268-007-9387-6

[60] Oosterhuis JK, van den Berg G, Monteban-Kooistra WE et al. Life-threatening Pneumocystis jiroveci pneumonia following treatment of severe Cushing's syndrome. Neth J Med 2007; 65: 215-217

[61] Stuijver D], van Zaane B, Feelders RA et al. Incidence of venous thromboembolism in patients with Cushing's syndrome: A multicenter cohort study. J Clin Endocrinol Metab 2011; 96: 3525-3532 doi:10.1210/jc.2011-1661

[62] Van Zaane B, Nur E, Squizzato A et al. Hypercoagulable state in Cushing's syndrome: A systematic review. J Clin Endocrinol Metab 2009; 94: 2743-2750 doi:10.1210/jc.2009-0290

[63] Koutroumpi S, Daidone V, Sartori MT et al. Venous thromboembolism in patients with Cushing's syndrome: Need of a careful investigation of the prothrombotic risk profile. Pituitary 2013; 16: 175-181 doi:10.1007/s11102-012-0398-4

[64] van der Pas R, Leebeek FW, Hofland LJ et al. Hypercoagulability in Cushing's syndrome: Prevalence, pathogenesis and treatment. Clin Endocrinol (Oxf) 2013; 78: 481-488 doi:10.1111/cen.12094

[65] Boscaro M, Sonino N, Scarda A et al. Anticoagulant prophylaxis markedly reduces thromboembolic complications in Cushing's syndrome. J Clin Endocrinol Metab 2002; 87: 3662-3666 doi:10.1210/ jcem.87.8.8703

[66] Berr CM, Stieg MR, Deutschbein T et al. Persistence of myopathy in Cushing's syndrome: Evaluation of the German Cushing's Registry. Eur J Endocrinol 2017; 176: 737-746 doi:10.1530/EJE-16-0689

[67] Rayes N, Quinkler M, Denecke T. [Surgical strategies for non-metastatic adrenocortical carcinoma]. Chirurg 2018; 89: 434-439 doi:10.1007/ s00104-017-0582-1

[68] Berr CM, Di Dalmazi G, Osswald A et al. Time to recovery of adrenal function after curative surgery for Cushing's syndrome depends on etiology. J Clin Endocrinol Metab 2015; 100: 1300-1308 doi:10.1210/ jc.2014-3632

[69] Hochberg Z, Pacak K, Chrousos GP. Endocrine withdrawal syndromes. Endocr Rev 2003; 24: 523-538 doi:10.1210/er.2001-0014

[70] Petersenn S, Honegger J, Quinkler M. National German Audit of Diagnosis, Treatment, and Teaching in Secondary Adrenal Insufficiency. Horm Metab Res 2017; 49: 580-588 doi:10.1055/s-0043-105077

[71] Clayton RN, Jones PW, Reulen RC et al. Mortality in patients with Cushing's disease more than 10 years after remission: A multicentre, multinational, retrospective cohort study. Lancet Diabetes Endocrinol 2016; 4: 569-576 doi:10.1016/S2213-8587(16)30005-5

[72] Bolland M], Holdaway IM, Berkeley JE et al Mortality and morbidity in Cushing's syndrome in New Zealand. Clin Endocrinol (Oxf) 2011; 75: 436-442 doi:10.1111/j.1365-2265.2011.04124.x 